\title{
TINJAUAN VISUAL PADA PERMAINAN DIGITAL INDONESIA BERJUDUL "DREADOUT"
}

\author{
Nadya $^{1}$, Hadi Saputra ${ }^{2}$ \\ ${ }^{I}$ Desain Komunikasi Visual, Universitas Bunda Mulia, Jakarta, nadya.ubm@gmail.com. \\ ${ }^{2}$ Desain Komunikasi Visual, Universitas Bunda Mulia, Jakarta, hadsapz@gmail.com.
}

\begin{abstract}
ABSTRAK
Di era digital sekarang ini, industri gim digital telah mengalami perkembangan yang sangat pesat. Hal ini juga diiringi dengan perkembangan visual grafiknya yang semakin meningkat, terutama pada aspek ruang tiga dimensi (3D). Negara Indonesia merupakan salah satu negara yang mengalami pengembangan gim 3D yang ditandai dengan bertumbuhnya para pakar industri lokal di bidang animasi dan gim tersebut. Selain itu, negara Indonesia juga merupakan salah satu negara di Asia Tenggara yang memiliki pendapatan ekonomi yang cukup berpotensi untuk menjadi yang terbesar pada sektor gim. Salah satu genre yang berpotensi menjadi populer di Indonesia adalah gim bergenre survival horror dengan judul "DreadOut". Genre ini menjadi alasan popularitas yang muncul karena masih banyak misteri di balik cerita horor di Indonesia yang belum terpecahkan sehingga dapat menarik baik masyarakat domestik maupun mancanegara.

Penelitian ini merupakan kajian visual tentang aset lingkungan dan desain karakter atau avatar pada salah satu gim lokal Indonesia berbentuk tiga dimensi. Selain itu, penelitian ini juga membahas sistem permainan, cerita, dan tata letak antarmuka pengguna pada gim tersebut. Metode yang digunakan adalah metode analisis kualitatif deskriptif dengan jenis penelitian eksplorasi particular, dimana peneliti melakukan pendekatan terhadap objek penelitian untuk menemukan pengetahuan khusus. Kesimpulan dari penelitian ini adalah untuk membuktikan apakah visualisasi permainan horror survival 3D di Indonesia dapat dinilai cukup baik dalam industri permainan kreatif.
\end{abstract}

Kata Kunci: Permainan Digital, Survival Horror, KajianVisual

\begin{abstract}
Game development is growing rapidly in this digital era. The graphic is also increasing more and more, especially in Three Dimensional space (3D). 3D game development is spreading around Indonesia. Now there are more local companies which making 3D games. Indonesia is one of the countries in Southeast Asia that have good enough game revenue to be the biggest one. One of the popular genre in Indonesia is survival horror. That's because horror
\end{abstract}


Indonesian stories is still have many unsolved mysterious things which can attract either domestic or foreign society. This study is including research about visualization such as $3 D$ object from the environments and character designs. Furthermore, game also getting influenced with its system which is played by user, and its storytelling as well. The game's layout (user interface) will categorized as a good one if it match with its theme and being consistent in visual and control. Good game must paying attention with all of those points. The conclusion of this research is to prove if $3 D$ survival horror game visualization in Indonesia can be rated good enough in creative game industries.

\section{Keywords:}

Game, Survival Horror, Visual Research

\section{PENDAHULUAN}

Perkembangan permainan digital atau biasa disebut sebagai gim digital di dunia semakin pesat, termasuk di Indonesia. Negara Indonesia sendiri terhitung sebagai negara dengan jumlah pendapatan gim yang cukup besar se-Asia Tenggara dalam skala global. Hal ini dikemukakan menurut riset yang dilakukan oleh situs riset pasar global yang bernama Newzoo.

Jika dilihat dari jenisnya, genre gim digital yang populer di kalangan masyarakat Indonesia adalah survival horror. Survival horrorgame adalah gim yang memiliki tujuan utama untuk menakuti pemainnya (player). Permainan ini biasanya dibumbui juga dengan cerita misteri yang sangat menegangkan dan menakutkan. Selain itu, jika dilihat dari genre cerita yang diminati, beberapa kalangan dari masyarakat Indonesia menyukai hal-hal yang berbau horor atau mistis. Hal ini dapat dilihat dari bermunculannya program dan acara di televisi yang mengandung unsur mistis, seperti Mister Tukul Jalan Jalan, Dunia Lain, Dua Dunia, dan sebagainya. Begitu pun dengan film-film horor Indonesia yang tengah beredar di dunia industri perfilman dalam negeri. Sebagian besar program acara tersebut memiliki rating penonton yang cukup tinggi. Hal ini menjadi bukti bahwa genre horor dengan unsur budaya Indonesia masih banyak dan dapat menjadi tema yang disukai masyarakat di Indonesia sehingga dapat menjadi peluang bagi industri gim untuk mengembangkan permainan digital dengan genre tersebut.

Salah satu gim buatan Indonesia yang bertemakan survival horroryaitu gim dengan judul "DreadOut", yang dibuat oleh Rumah Produksi bernama Digital Happiness. Game ini terbukti sebagai karya Rumah Produksi Digital Happiness yang berhasil menjual produknya sebanyak 10.000 kopian permainan pada bulan pertama dengan harga satuan 14.99 dollar AS (http://tekno.kompas.com). pemain yang memainkan gim ini dapat merasakan suasana latar 
belakang Indonesia yang kuat dan hal ini belum pernah ada sebelumnya pada gim buatan lokal lainnya.

Berdasarkan hal itu peneliti menganalisis gim berjudul "DreadOut" dari suudut pandang visual sehingga dapat menjadi referensi bagi peneliti lain bahkan bagi para pengembang gim lokal untuk menciptakan permainan digital dengan tema serupa yang lebih kreatif dan inovatif.

\section{TINJAUAN PUSTAKA}

\section{Desain Komunikasi Visual}

Menurut Yongky Safanayong (2006:12), dalam bukunya yang berjudul "Desain Komunikasi Visual Terpadu", ia mengatakan bahwa Desain berasal dari kata designare (Latin) yang artinya meren-canakan atau merancang. Selain itu desain berasal dari kata disegno (Italia), dessein (Prancis) yang artinya gambar.

\section{Teori Layout}

Menurut Gavin Ambrose dan Paul Harris (2005:6), layout adalah tata letak penempatan gambar dan teks dalam sebuah elemen desain.Layout dapat membantu atau menghalangi penerimaan informasi disajikan dalam sebuah karya. Layout yang kreatif dapat memberikan nilai lebih bagi para pembaca, sedangkan tata letak yang sederhana dapat memungkinkan konten untuk lebih mudah dicerna. (Gavin Ambrose dan Paul Haris, 2005:6)

Layout memiliki beberapa prinsip dasar, antara lain:

1. Urutan (Sequence)

2. Penekanan (Emphasis)

3. Keseimbangan (Balance)

4. Kesatuan (Unity)

\section{Teori Warna}

Menurut Gavin Ambrose dan Paul Harris (2005:11), warna adalah elemen pertama yang diperhatikan ketika melihat suatu objek pertama kali. Warna adalah elemen kunci dari desain grafis, sebuah alat yang dapat digunakan untuk menarik perhatian, mengarahkan pandangan, dan memberitahu audience tentang reaksi yang terjadi saat informasi diberikan.Dalam pembagian warna, digunakan sebauah lingkaran warna (color wheel). Warna-warna dalam lingkaran warna terdiri atas tiga bagian, yaitu:

1. Warna primer, terdiri atas warna merah, kuning, dan biru. Warna primer merupakan dasar dalam lingkaran warna.

2. Warna sekunder, terdiri atas oranye, hijau, dan ungu. Warna sekunder merupakan pencampuran dua warna primer dengan perbandingan yang sama.

3. Warna tersier merupakan pencampuran warna primer \& sekunderdisampingnyadengan perbandingan yang sama.

\section{Teori Tipografi}

Menurut Danton Sihombing (2015:13), tipografi merupakan suatu ilmu dalam memilih dan menata huruf dengan pengaturan penyebarannya pada ruang-ruang yang tersedia, untuk 
menciptakan kesan tertentu, sehingga dapat menolong pembaca untuk mendapatkan kenyamanan membaca semaksimal mungkin. Beberapa prinsip tipografi antara lain legibility, readability, visibility, dan clarity

\section{Teori Logo}

Logo adalah singkatan dari logotype. Istilah logo baru muncul tahun 1937 dan istilahnya lebih populer dibandingkan logotype. Asal kata logo berasal dari bahasa Yunani logos, yang berarti kata, pikiran, pembicaraan, akal budi. Pertama kali, istilah logotype muncul lebih dahulu di tahun 1810-1840, yang diartikan sebagai tulisan nama entitas (objek sebenarnya yang dimasukkan) yang didesain secara khusus dengan menggunakan teknik lettering atau memakai jenis huruf tertentu. Jadi, awal logotype hanya elemen tulisan saja.

Fungsi dari logo adalah:

1. Identitas diri, untuk membedakannya dengan identitas milik orang lain.

2. Tanda kepemilikan.

3. Tanda jaminan kualitas.

4. Mencegah peniruan/pembajakan.

\section{Teori Desain Karakter}

Setiap karakter mempunyai archetype. Archetype adalah mempelajari sifat-sifat dasar manusia dan peran yang mereka mainkan dalam kehidupan. Penggunaan ini awalnya digunakan oleh Carl Jung dalam psikologi.

Menurut Andrew Rollings dan Ernest Adams (2003:137-144), kategori dalam archetype karakter dalam game antara lain:

1. Hero, pusat dari cerita

2. Mentor, karakter yang memandu hero.

3. Higher self, cita-cita/tujuan karakter yang dinginkan hero.

4. Allies adalah karakter yang ditempatkan dalam game untuk membantu hero.

5. Shape Shifter, biasanya dibuat misterius dan diungkapkan setelah cerita sebagai cerita lain atau dalam game biasa disebut Downloadable Content (DLC) atau cerita tambahan.

6. Threshold guardian, karakter yang menghambat progres hero.

7. Trickster, merupakan karakter netral yang senang mempermainkan hero.

8. Shadow,merupakan karakter antagonis yang suka menentang hero.

9. Herald, pendamping hero dengan perubahan arah dan memberikan motivasi kepada hero untuk melanjutkan cerita.

\section{Teori User Interface}

Menurut Wilbert O. Galitz (2007:45-58), perancangan user interface memiliki prinsipprinsip yang umum, antara lain:accessibility, aesthetically pleasing, availability, clarity, compability, configurability, consistency, control, directness, efficiency, familiarity, flexibility, forgiveness, immersion, obviousness, operability, perceptibility, positive first impression, predictability, recovery, responsiveness, safety, simplicity, transparency, trade-offs, dan visibility. 


\section{METODE PENELITIAN}

Metode dalam perancangan diantaranya metode kualitatif yang berupa observasi (pengamatan)dan studi kasus dengan pendekatan deskriptif. Studi kasus akan mencermati kajian visualisasi dalam game. Untuk teknik pengumpulan datanya menggunakan metode observasi dalam hal ini adalah gim berjudul "DriedOut" dan kajian teori yang sesuai dengan lingkup Desain Komunikasi Visual.

\section{HASIL PENELITIAN DAN PEMBAHASAN} berikut.

Analisis terhadap visualisasi dalam game "DreadOut" tersebut dapat diuraikan sebagai

\section{DreadOut}

"DreadOut" merupakan game berbasisPC yang menarik perhatian pengguna Steam (distributor game) setelah masuk dalam 100 peringkat di Steam Greenlight pada tanggal 15 Januari 2013. Game yang dibuat oleh Digital Happiness ini kemudian menjadi game Indonesia pertama yang berhasil masuk Steam dan dirilis pada 16 Mei 2014.

"DreadOut" merupakan pengembangan dari game sederhana berjudul "Jurig Escape", yang hanya merupakan game aksi tembak-menembak musuh.

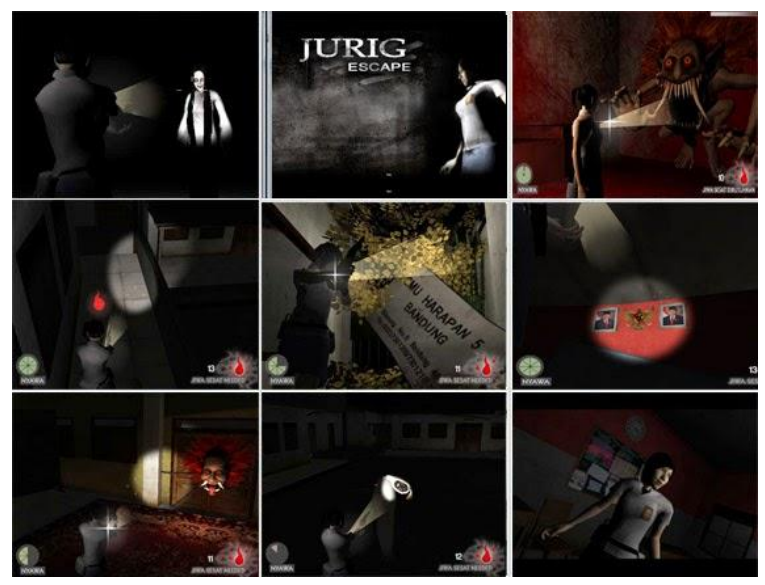

Gambar 1. Beberapa Screenshot Game "Jurig Escape"

Sumber: pribadi (2018) 


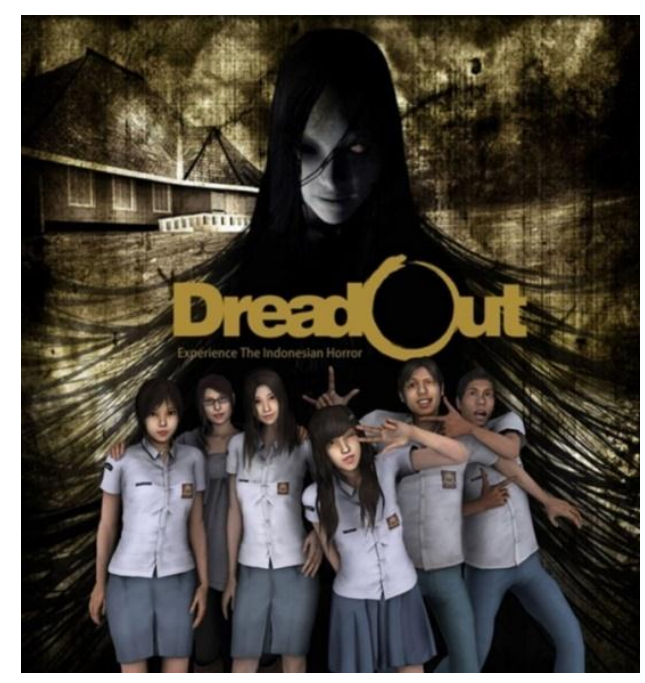

Gambar 2. CoverGame PC "DreadOut"

Sumber: pribadi (2018)

\section{Sinopsis}

"DreadOut" bercerita tentang sekelompok murid SMA tersesat dari perjalanan liburan mereka, mereka menemukan sebuah kota tua yang telah ditinggalkan. Mereka tidak menyadari sesuatu yang jahat sedang bersembunyi. Kota itu pun memperlihatkan sisi gelap dan rahasia yang menyedihkan. Linda, protagonis game ini, menyadari sesuatu yang aneh dan mistis terjadi pada dirinya. Dia memperoleh kekuatan supernatural yang bisa menyelamatkan dia dan temantemannya dari ancaman supernatural asing.

\section{Tipografi dan Logo}

Dalam logonya, DreadOut meng-gunakan jenis fontsans-serif yang tebal dengan bagian "O" yang dibuat menyerupai ular yang melingkar. Hal ini juga diterapkan pada halaman preloader Gim tersebut.Tipografi keseluruhan untuk informasi yang digunakan dalam gim adalah jenis huruf Arial yang dapat dikatakan terlalu sederhana dan kurang sesuai dengan tema horror.

\section{ABCDEFGHIJKLMNOPQRSTUVWXYZ abcdefghijklmnopqrstuvwxyz}

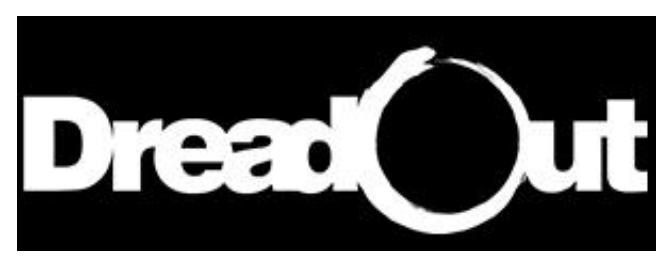

Gambar 3. Tipografi dan Logo DreadOut

Sumber: pribadi (2018) 


\section{Tinjauan Desain Karakter}

\section{Karakter Utama}

Berikut ini adalah karakter-karakter yang terdapat pada gim DreadOut:

\section{Linda Mellinda}

Linda adalah karakter utama yang keras kepala dengan sifat pendiam. Ia terlihat teguh dari luar, namun sensitif di dalam. Ia dapat mendahulukan kepentingan temannya dibandingkan dirinya sendiri. Ia terkadang ceroboh, namun intuisinya dapat mendorongnya melewati halangan yang dihadapinya.

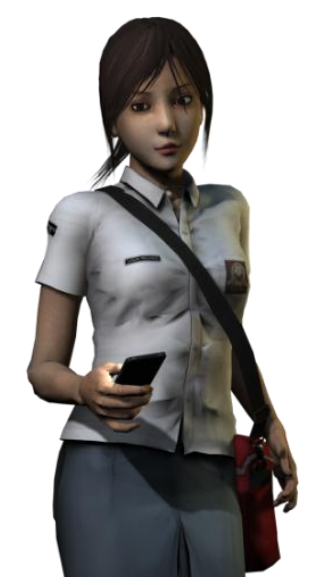

Gambar 4. Karakter Linda Mellinda

Sumber: pribadi (2018)

Linda memakai baju sekolah SMA Indonesia dengan rok span dan sepatu hitam, sesuai aturan sekolah. Ia memiliki rambut hitam yang diikat ke belakang dengan poni panjang menutupi dahi bagian kanan. Matanya yang hitam akan berubah merah jika ada hal spiritual terjadi (terlihat di permulaan game). Linda juga menggunakan kalung perak dan membawa tas berwarna merah, serta smartphone hitam atau kamera SLR dalam gim untuk melawan hantu dan membantu menelusuri area gelap.Archetype yang dimiliki Linda adalah hero, karena ia adalah protagonis utama yang dimainkan pemain.

Jika ditinjau dari sisi desain karakter, sifat Linda yang aktif terlihat dari cara berpakaian yang cenderung lebih ketat dibanding seragam lainnya. Bentuk rambut yang diikat ke belakang juga memperkuat sosoknya yang aktif. Warna merah pada tas dan mata Linda merupakan representasi dari kekuatannya yang aktif dan sesuai sifatnya yang keras.

\section{Shakira Irawati (Ira)}

Ira adalah sahabat Linda. Ia memiliki sifat yang peduli terhadap sesama. Meski pemalu dan agak pendiam, ia suka tertawa. Ia berkepribadian manis, ceria, dan lemah lembut, terutama saat Linda di dekatnya. Ira berumur 18 tahun, satu tahun di atas Linda yang berumur 17 tahun. 


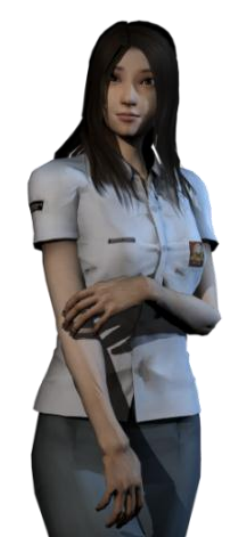

\section{Gambar 5. Karakter Ira}

Sumber: pribadi (2018)

Ira memakai baju sekolah SMA sama seperti Linda. Ia memiliki rambut panjang dan poni yang menutupi bagian kanan wajahnya.Archetype yang dimiliki Ira adalah mentor, karena ia selalu membantu Linda sebagai hero dalam menunjukkan jalan dalam gim.

\section{Mariska Gandasasmita (Ms. Siska)}

Ms. Siska berasal dari keluarga kaya. Ia mengajar karena passion (kegemaran) dan banyak siswa yang mempercayai dirinya untuk konseling dan kebijaksanaan. Sebagai seorang yang dewasa, ia mempunyai rasa tanggung jawab yang besar kepada siswa-siswanya dan sangat perhatian pada keselamatan mereka.

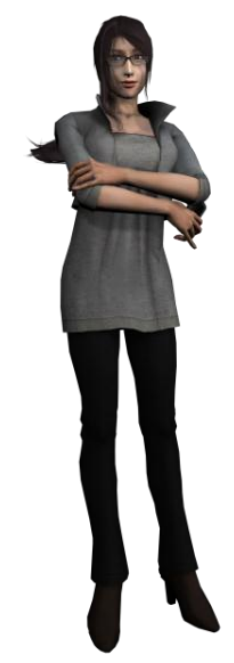

Gambar 6. Karakter Ms. Siska

Sumber: pribadi (2018)

Siska berumur 25 tahun. Ia memakai pakaian blazer abu-abu dan celana panjang (trouser)hitam. Ia juga memakai kacamata dengan frame hitam dengan rambut seperti Linda namun dengan poni yyang panjang dan keriting.Archetype yang dimiliki Ms. Siska dapat juga disebut sebagai shaft shifter, karena meninggalkan hal misterius yang tak terjawab dalam gim. Siska dapat bersifat sebagai teman (ally)ataupun musuh(enemy). 


\section{Shelly Angelia}

Shelly adalah pemandu sorak (cheerleader)yang terkenal di sekolahnya. Ia karakter yang terlalu aktif dan bersemangat, yang terkadang dapat mengganggu. Hal tersebut juga dapat diasumsikan dari suara yang dimilikinya.Shelly suka mengikuti Ms. Siska kemana-mana dan masih kekanak-kanakan. Terkadang lancang terhadap orang lain.

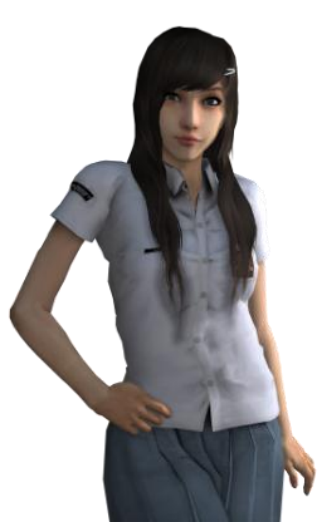

Gambar 7. Karakter Shelly

Sumber: pribadi (2018)

Shelly digambarkan seperti anak gadis sekolah SMA berumur 18 tahun. Ia menggunakan rok sekolah jenis kembang (rempel). Ia berambut hitam panjang sampai ke siku tangan dan memakai jepit rambut di bagian kiri. Ia juga selalu membawa smartphone berwarna merah muda (pink).

Archetype yang dimiliki Shelly dapat juga disebut sebagai allies, karena ia bersama-sama dengan hero terperangkap di kota tempat gim berlangsung.

\section{Doni Maulana}

Doni adalah kapten tim basket di sekolahnya. Ia suka menunjukkan keberaniannya. Ia adalah saudara ipar dari Shelly.Doni seorang yang periang dan menyukai petualangan. Ia melakukan segala sesuatu dengan berani tanpa memikirkan bahaya dari tindakan yang dilakukannya.

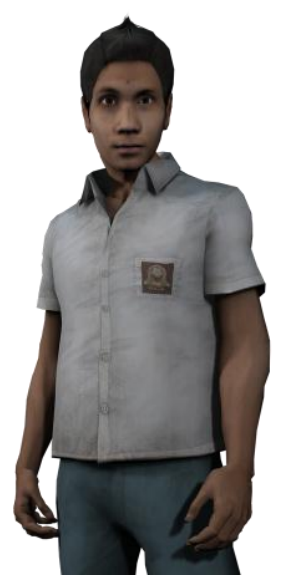

Gambar 8. Karakter Doni

Sumber: pribadi (2018) 
Doni memakai baju sekolah SMA dan memiliki kulit yang agak gelap dan rambut yang berdiri. Ia terlihat memiliki titik gelap kecil di dahinya.Archetype yang dimiliki Doni dapat juga disebut sebagai allies juga, karena ia bersama-sama dengan Linda dan yang lainnya terperangkap di kota tempat game berlangsung. Dari karakter ini dapat dilihat bahwa Doni merupakan perwujudan keragaman ras di Indonesia yang ingin diperlihatkan oleh pengembang gim tersebut.

\section{Yayan}

Yayan adalah anak yang dianggap pintar dalam sains dan matematika. Ia dikenal karena kritiknya yang kasar.Yayan adalah seorang yang pintar seperti yang dikatakan Shelly. Shelly juga mengatakan bahwa Yayan adalah sosok yang "mesum".Yayan memiliki rambut hitam yang membentang ke kanan wajahnya. Ia juga sedikit gemuk.Archetype yang dimiliki Yayan dapat juga disebut sebagai allies, sama seperti Shelly dan Doni.

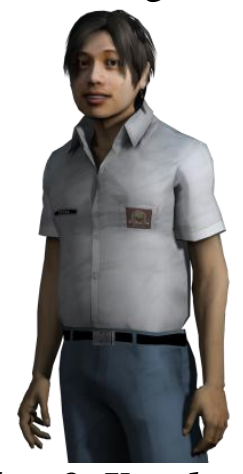

\section{Gambar 9. Karakter Yayan}

Sumber: pribadi (2018)

\section{Karakter Hantu (Musuh/Enemy)}

Berikut ini adalah hantu-hantu (musuh) yang ditemui Linda. Musuh-musuh ini berperan sebagai threshold guardian, karena bersifat menghambat hero (Linda) dalam perjalanannya.

\section{Pocong}

Pocong adalah mayat yang dibungkus kain kafan, dengan prinsip yang sama seperti mumi. Pocong dalam game DreadOut ada 3 macam yaitu Pocong (normal), Pocong Warrior (Pocong yang tangan dan kakinya keluar serta memegang sabit di tangan kanan), dan Pocong di motor (hantu bonus dalam game).

\section{Genderuwo}

Dalam budaya Indonesia, Genderuwo sering disebut jin atau makhluk halus yang menyerupai kera dengan bulu tipis dan berukuran raksasa. Wajahnya sering terlihat seperti binatang dengan mata merah besar dengan taring gigi yang panjang. Genderuwo biasanya berada dalam hutan bamboo saat malam. Mereka juga suka menarik perhatian perempuan.

\section{Kuntilanak}

Kuntilanak adalah hantu wanita Indonesia yang meninggal saat hamil. Kemunculan kuntilanak ditandai dengan suara tawa dengan nada tinggi. 


\section{Babi Ngepet}

Babi Ngepet adalah babi dalam mitologi Jawa yang dikatakan sebagai wujud orang yang menggunakan ilmu hitam agar cepat kaya.

\section{Sundel Bolong}

Sundel Bolong berasal dari mitologi Jawa yaitu perempuan sundal dengan lubang di bagian punggung. Sundel Bolong sering digambarkan sebagai wanita berambut panjang dengan gaun putih panjang seperti kuntilanak.

\section{Sewurupa}

Sewurupa adalah hantu yang tidak berbahaya dalam game. Sewurupa adalah manifestasi dari keabadian (Immortality).

\section{Demit Lorong}

Demit Lorong adalah demit (ras jin) di suatu area terisolasi. Dalam hal ini, musuh ini hanya berada di koridor tak berujung yang ada dalam game. Demit diberikan tugas untuk menjaga tempat mereka hidup. Demit dapat berbentuk apapun yang menyerupai manusia.

8. Demit Pintu

Demit Pintu adalah demit yang berada di area pintu mistis yang dipercaya menjadi penghubung antara dunia nyata dengan tanah orang mati dalam game.

\section{Tuyul}

Tuyul digambarkan makhluk supernatural berwujud anak kecil tak berambut, dan memiliki sifat kekanak-kanakan yang dimaksudkan bodoh atau tidak tertalu pintar. Tuyul Centeng adalah tuyul yang besar dalam game.

10. Palasik

Palasik dikenal sebagai makhluk pengisap darah. Palasik digambarkan hantu kepala terbang dengan organ-organ yang melekat pada tulang belakang yang menjalar dari kepala.

11. Matianak

Matianak berasal dari kata "mati" dan "anak" yang dikombinasikan menjadi kematian seorang anak.Matianak memiliki penampilan yang hamper mirik dengan kuntilanak. Dalam game, Matianak hanya terlihat melalui kamera dan berdiri diam di suatu area.

\section{Gundul Pringis}

Gundul Pringis digambarkan berupa kepala orang yang meninggal dimutilasi. Makhluk ini sering tertawa dan dilakukan sambil menggelinding.

\section{Jurig Pengantin}

Hantu ini adalah hantu pasangan yang menikah. Terdapat luka memar pada dagu sang lakilaki, dan leher perempuan. 

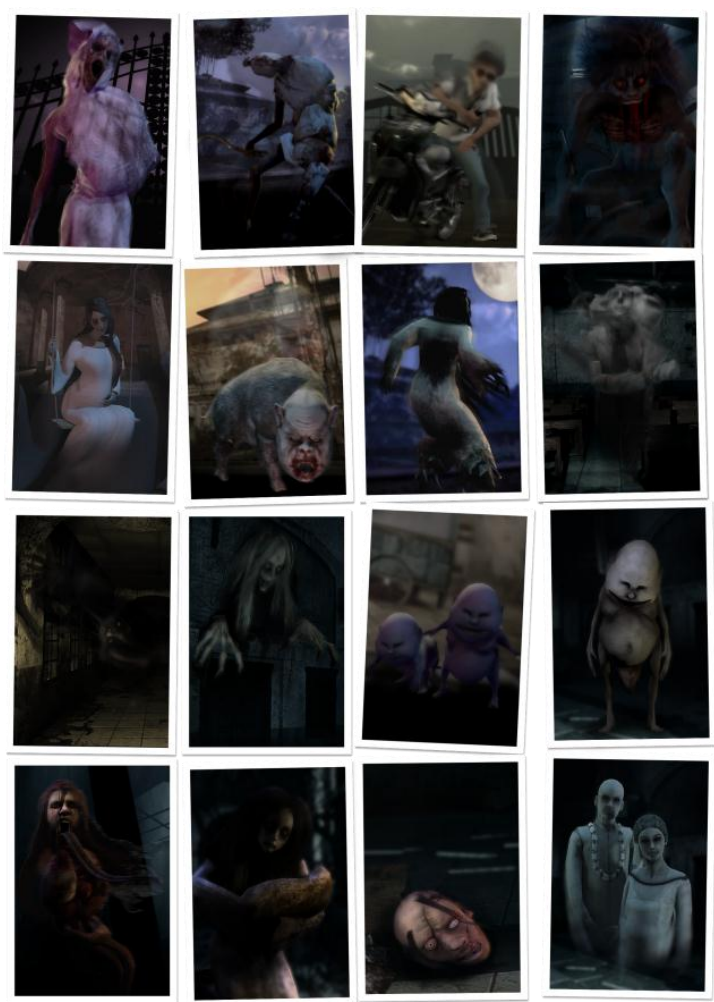

\section{Gambar 10. Hantu-Hantu dalam Game DreadOut yang Sering Ditemukan dalam Cerita Mistis \\ Sumber: pribadi (2018)}

\section{Hantu Gunting (Scissors Phantom)}

Hantu gunting adalah hantu buatan DreadOut. Hantu gunting adalah hantu kepala sekolah yang suka berbusana wanita. Ia terlalu obsesi dengan keibuan sehingga mengganggap sebuah boneka anaknya. Ia paranoia terhadap kuntilanak di tempat tinggalnya. Hantu gunting merupakan bos pertama yang harus dilawan dalam game.

\section{Pocong Radja}

Hantu dukun yang gemar memakai ilmu hitam seperti pelet, susuk, dan santet. Ia meninggal karena kesalahannya dalam ilmu hitam. Pocong Radja merupakan bos kedua yang akan dihadapkan pada pemain.
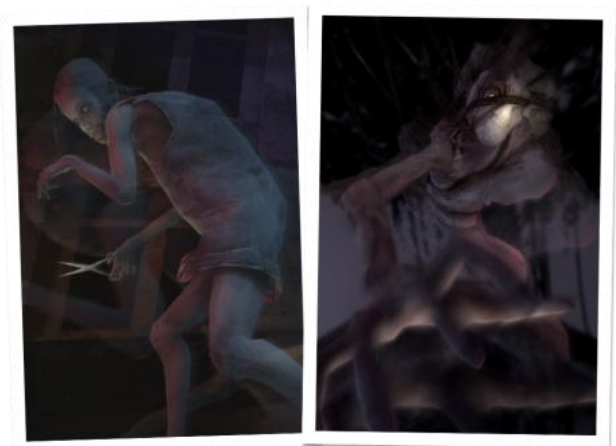

Gambar 11. Hantu Gunting dan Pocong Radja 
Sumber: pribadi (2018)

\section{Second Sister}

Saudara perempuan kedua yang hanya dapat dilihat melalui cermin. Karakter ini digambarkan menggunakan baju robek-robek dengan beberapa potongan rambut. Kondisi fisiknya adalah cacat dan lumpuh, sehingga tidak dapat berjalan dan berbicara.

\section{Third Sister}

Saudara perempuan ketiga yang paling muda dan hanya berbentuk boneka bernama Suzi. Ia terlihat berbentuk sepasang tangan di belakang Ira dalam game.

\section{First Sister}

Saudara perempuan tertua dan karakter antagonis utama di game DreadOut. Ia dikenal juga sebagai Lady in Red (Wanita Berbaju Merah).Archetype yang dimilikinya adalah shadow karena ia adalah antagonis utama.
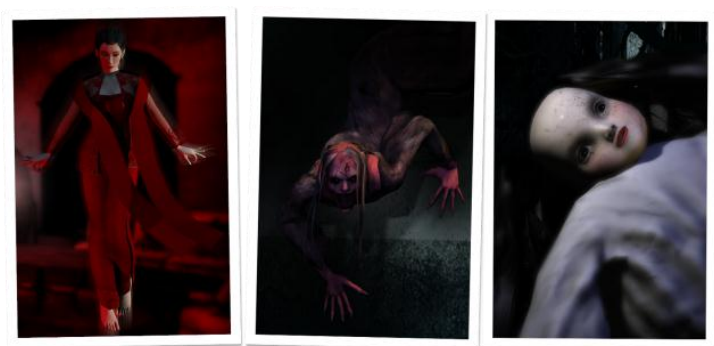

Gambar 12. Tiga Saudara Perempuan dalam Game DreatOut (Tua-Muda)

Sumber: pribadi (2018)

\section{DreadOut - Keepers of The Dark}

Downloadable Content (DLC) adalah konten tambahan yang berupa bonus dari konten game sebelumnya. DreadOut memiliki DLC yang berjudul "DreadOut: Keepers of The Dark" pada tanggal 26 Maret 2016.

DLC ini bersifat stand-alone (tidak membutuhkan game original). Game ini lebih berfokus pada gameplay dimana Linda, sang protagonis menjelajahi dunia cermin, dimana terdapat 8 area kekuasaan yang harus dilalui. pemainharus mengalahkan hantu-hantu di setiap area untuk menamatkan game ini.

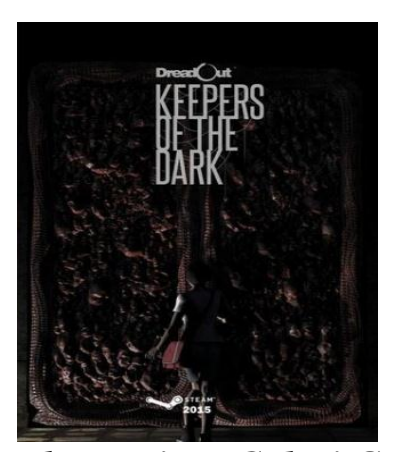

Gambar 13. Ilustrasi DLC dari Game DreadOut

Sumber: pribadi (2018) 


\section{Desain Environment}

Lokasi environment yang terdapat dalam keseluruhan game "DreadOut" antara lain:

1. Area pondok, gang sempit, dan rumah kos dalam demo

2. Area kota yang ditinggalkan

3. Area sekolah tua desain tahun 2000-an

4. Area di luar sekolah, gang sempit, dan perumahan kampung Indonesia

5. Area kereta

6. Hutan dengan pohon lebat

7. Area hutan dengan kolam

8. Pepohonan

9. Area dalam rumah besar (mansion)

10. Area limbo (tempat player respawn/mengulang saat game over; gagal dalam game)

11. Area battle dengan Demit Pintu

12. Area battle dengan Lady in Red (First Sister)

13. Area kuburan

14. Area saluran (sewer) dalam ruang 104 dalam DLC

15. Area ruang pemilihan stage (DLC)

16. Area ruang 101 dalam DLC yang berupa area pemandian yang luas seperti saluran air dan area yang terlihat astral/suci karena tekstur pada tembok dalam area tersebut.

17. Area battle dengan Serpent Mistress.

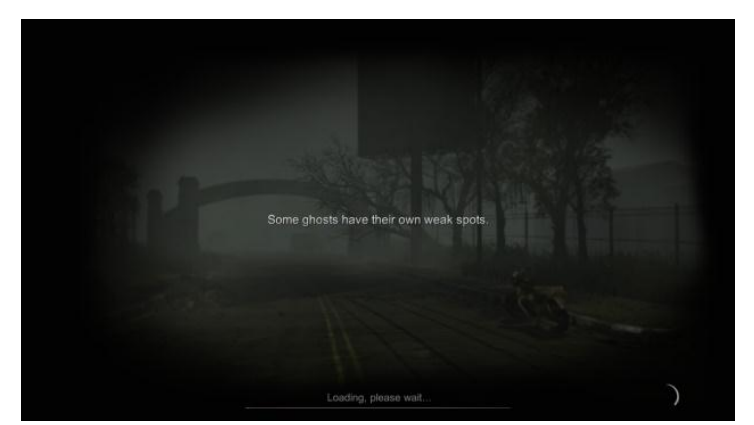

Gambar 16. Salah satu layar loading dalam user interface "DreadOut" Sumber: pribadi (2018)

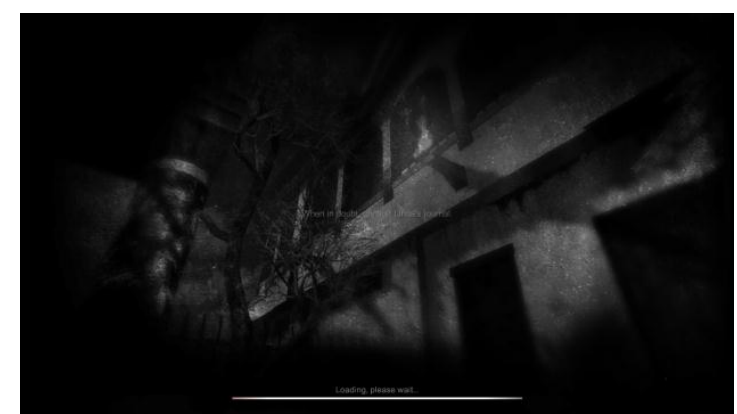

Gambar 17. Ilustrasi Area Sekolah (dalam layar loading)

Sumber: pribadi (2018) 
Gambar 18. Ilustrasi Area Hutan dengan Kolam (dalam layar loading)

Sumber: pribadi (2018)

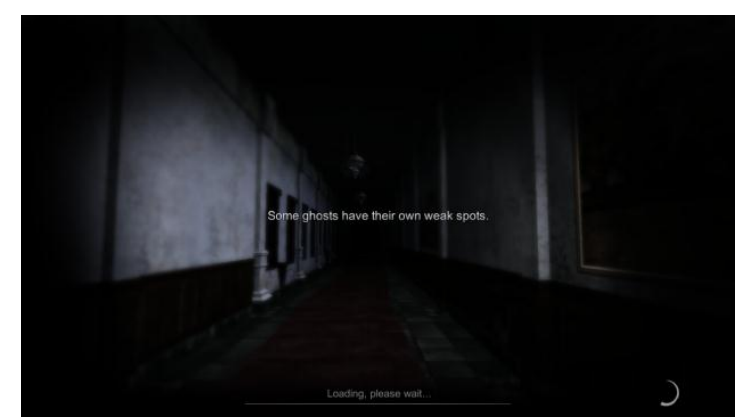

Gambar 19. Ilustrasi Area Mansion (dalam layar loading)

Sumber: pribadi (2018)

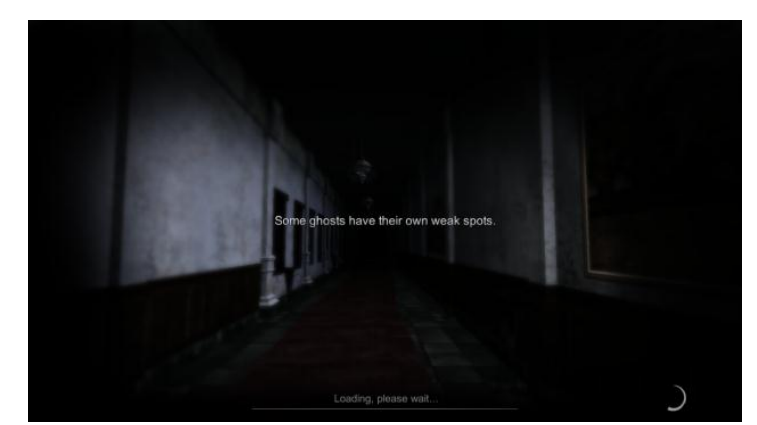

Gambar 20. Salah satu ilustrasi dalam "DreadOut :Keepers of The Dark" (dalam layar loading)

Sumber: pribadi (2018)

Tampilan desain karakter dari DreadOut sudah cukup bagus sebagai objek 3D, begitu pun pada bagian environment. Tidak heran jika DreadOut dalam pengembangannya sudah dikenal sampai ke kancah internasional.

\section{User Interface}

Berikut ini adalah analisis prinsip user interface pada game "DreadOut":

1. Accessibility

Sistem yang dirancang sudah dapat digunakan (usable).

2. Aesthetically Pleasing

"DreadOut" menyediakan visual dari desain environment yang terdapat dalam layar main menu dan loading.

3. Availability 
Hal ini dapat dilihat dari galerifoto yang tersimpan saat player menggunakan kamera/smartphone dalam gameplay.

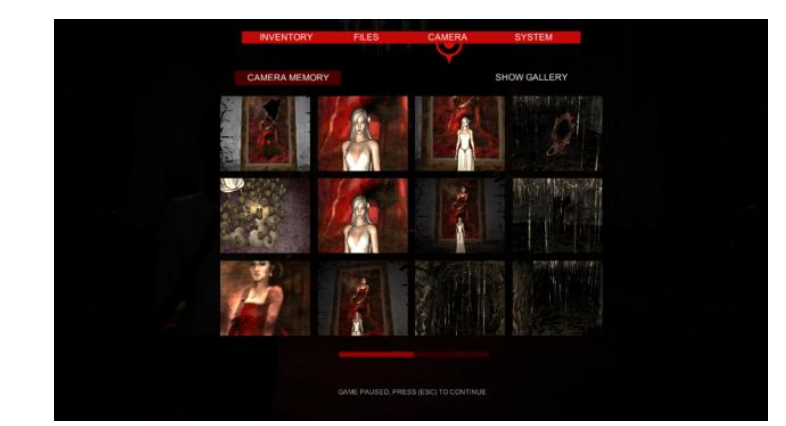

Gambar 21. Layar galeri pada game "DreadOut"

Sumber: pribadi (2018)

\section{Clarity}

Desain user interface sudah baik secara visual dan penggunaan kata yang dipakai dapat dimengerti oleh user.

5. Compability

Beberapa task dalam game sudah sesuai dengan fungsinya.

6. Configurability

Hal ini dapat dilihat dari vignette merah dan biru dalam gameplay. Warna merah yang menandakan musuh yang dekat, sedangkan warna biru menandakan petunjuk yang dekat, sedangkan kecacatan ( glitch) pada kamera dapat menandakan area yang harus difoto/diklik oleh player.

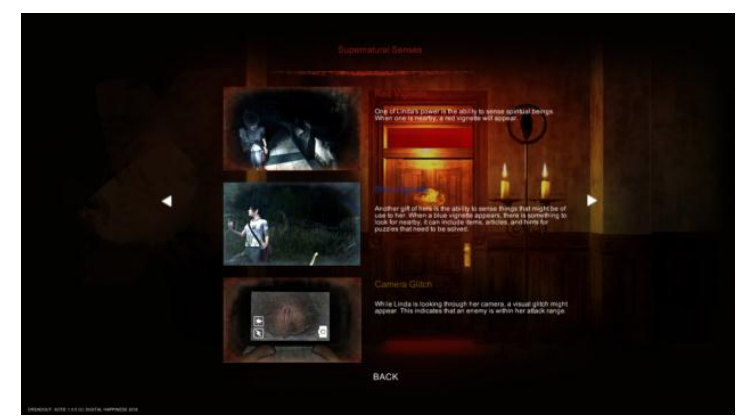

Gambar 22. Petunjuk warna vignette dalam game "DreadOut"

Sumber: pribadi (2018)

7. Consistency

Terdapat tindakan yang sama selalu menghasilkan hal yang sama, sehingga player sudah mengerti dengan cepat fungsi yang diberikan.

8. Control

User dapat mengontrol interaksi, segala tindakan yang dilakukan system dalam layar setting. 


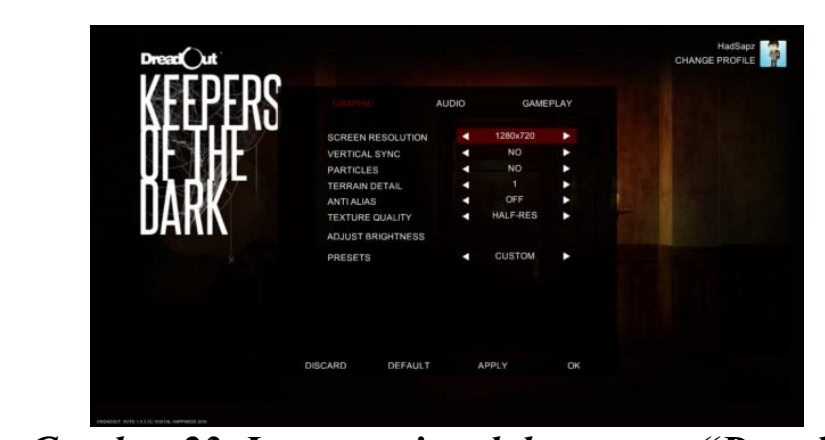

Gambar 23. Layar setting dalam game "DreadOut"

Sumber: pribadi (2018)

\section{Directness}

Dalam layar loading, player diberikan informasi berupa petunjuk dalam menyelesaikan permainan.

10. Efficiency

Sistem hanya memberikan informasi yang perlu diperhatikan user dalam satu momen tertentu.

11. Familiarity

Sistem dapat menerapkan konsep dan bahasa yang mudah dikenal oleh user.

12. Flexibility

Player akan semakin mengerti apa yang fungsi-fungsi task seiring berjalannya game.

13. Forgiveness

Sistem dapat menyediakan pesan ketika player bosan menunggu layar loading yang terlalu lama. Namun pada dasarnya masih banyak eror/bug pada gameplay di samping user interface.

14. Immersion

Player mendapat kepuasan karena hal baru yang terdapat dalam game "DreadOut", yaitu visualisasi unsur Indonesia.

15. Obviousness

Sistem mudah dipelajari dan mudah dimengerti.

16. Operability

Sistem dapat digunakan oleh setiap pengguna Steam.

17. Perceptability

User dapat merasakan dan mempersepsikan sistem yang dirancang.

18. Positive First Impression

Sistem menyediakan tampilan layar yang sedikit namun dapat dimengerti oleh player.Selain itu, player dapat memikirkan kemungkinan yang terjadi pada pilihan yang tersedia.

19. Predictability

Player dapat mengantisipasi progres/kemajuan alami dari setiap task.

20. Recovery

Sistem mengizinkan perintah atau tindakan yang dihapus, ditolak, atau tidak diinginkan user.

21. Responsiveness

Sistem dengan cepat merespon permintaan pengguna yang mencakup visual, teks, dan audio. 
22. Safety

Sistem harus dapat melindungi user membuat kesalahan.

23. Simplicity

Simplicity karena sederhana, tidak banyaknya informasi yang diberikan pada user, namun user tetap dapat mengerti fungsi dari setiap task yang diberikan. Sistem hanya memberikan tampilan yang berguna saja dalam momen tertentu, seperti yang terdapat pada layar setting. Pilihan dalam layar main menu sudah tidak diperlukan sehingga dihilangkan.

24. Transparency

Sistem memfokuskan user dalam task, tanpa mempedulikan mekanisme pada interface.

25. Trade-Offs

Sistem mendahulukan kebutuhan penggunanya dibandingkan dengan kebutuhan teknis.

26. Visibility

Status pada sistem dan metode penggunaannya sudah jelas terlihat, baik dari segi visual dan teks.

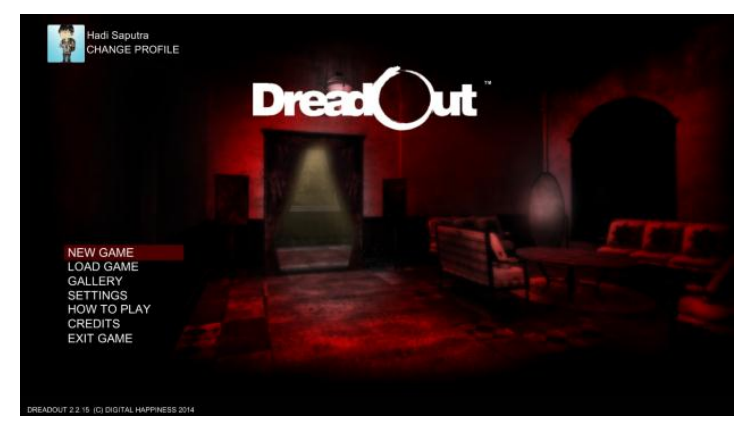

Gambar 24. Screenshot layar Main Menu pada game "DreadOut"

Sumber: pribadi (2018)

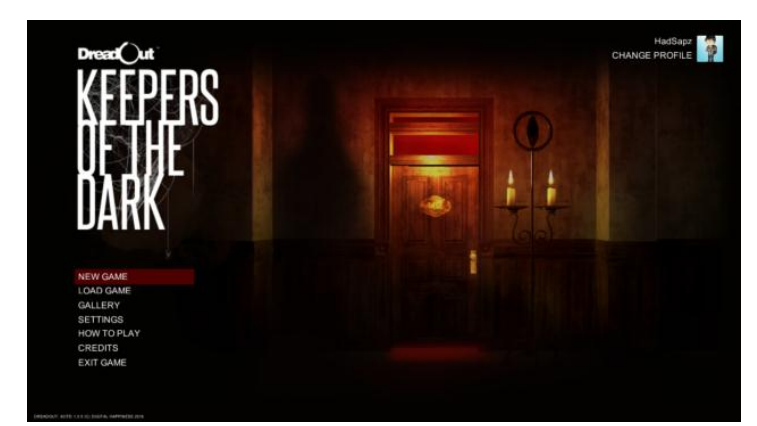

Gambar 25. Screenshot layar Main Menu pada DLC game "DreadOut"

Sumber: pribadi (2018)

Pemilihan tipografi pada user Interface dalam game DreadOut dapat dikatakan kurang sesuai dengan tema horror. Sehingga pendekatan artistik yang didapat belum terasa suasana horornya. Namun keterbacaan dari teks sudah dapat terlihat kuat.

Berdasarkan analisis terhadap prinsip user interface yang ditekankan dalam game "DreadOut" maka dapat disimpulkan bahwa, Gim ini menerapkan prinsip desain interface 
diantaranya adalahflexibility pada layar loading, simplicity pada layar menu utama, efficiency, dan aesthetically pleasing dengan ilustrasi di setiap layar sesuai dengan kegunaannya, sehingga user masih dapat menikmati permainan.

\section{Gameplay}

Gameplay "DreadOut" menggunakan third-person perspective (yaitu player dapat melihat karakter yang digunakan dalam bermain, yaitu Linda. Selain itu, game ini juga menggunakan pandangan first-person perspective pada saat mode kamera. Secara keseluruhan, game "DreadOut" terbagi menjadi beberapa bagian.

\section{Act 0 (Demo)}

Act 0 adalah demo atau first-playable game digunakan untuk memberikan daya tarik sehingga membantu voting di Indiegogo yang berguna untuk pendanaan game.Dalam act ini, Linda terbangun di sebuah pondok tua dan kemudian menelusuri gang hingga menemukan rumah kos dan keluar ke arah kuburan.

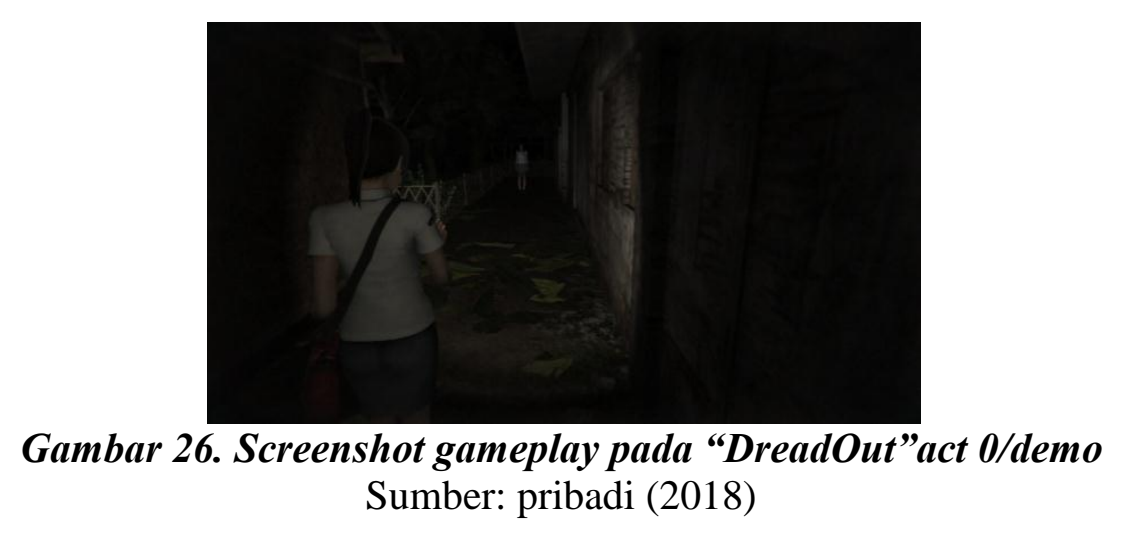

Act 1

Pada Act 1, diperkenalkan kota tua yang sudah ditinggalkan, sisanya player hanya menghabiskan waktu di dalam gedung sekolah sampai pada akhir Act 1. Namun hantu Indonesia yang dihadapi player yang mempunyai keunikan masing-masing yang belum pernah terlihat dalam game lain sebelumnya sehingga terhindar dari kebosanan.

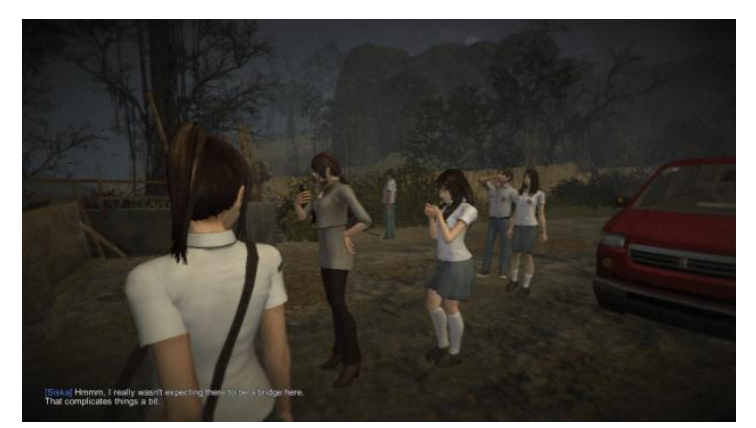

Gambar 27. Screenshot gameplay pada "DreadOut"act 1

Sumber: pribadi (2018)

Act 2 
Pada Act 2, ruang yang dieksplorasi lebih luas, tidak hanya terpaku pada satu area tertutup seperti pada Act 1, sehingga gameplay meningkat.

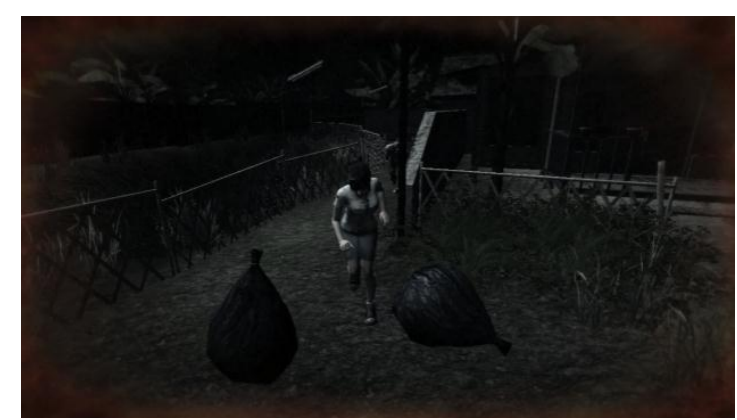

Gambar 28. Screenshot gameplay pada "DreadOut"act 2

Sumber: pribadi (2018)

\section{DLC - Keepers of The Dark}

DLC memakai area-area dari Act sebelumnya dengan 3 area baru, yaitu area selokan (sewer), area mirror realm, dan area final battle. Hantu-hantu baru yang diciptakan masih dapat menghibur player, karena mekanisme battle dengan hantu tersebut menjadi hal yang baru lagi.

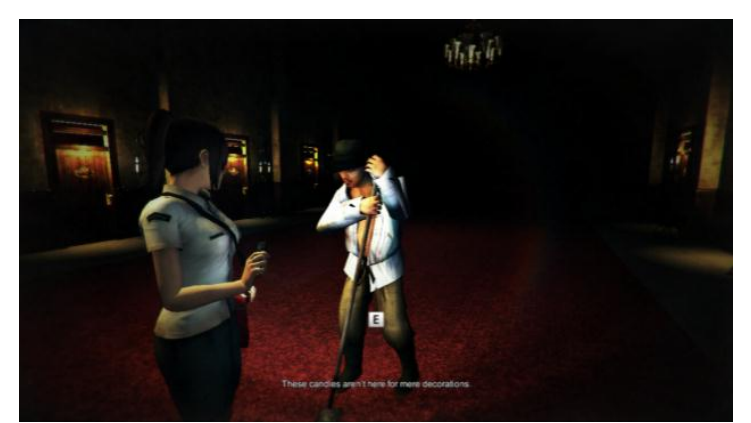

Gambar 29. Screenshot gameplay pada "DreadOut: Keepers of The Dark" Sumber: pribadi (2018)

\section{KESIMPULAN DAN IMPLIKASI}

Dari uraian penelitian ini, maka dapat disimpulkan bahwa tinjauan visual dalam gim "DreadOut" sudah menerapkan teori dan kaidah yang baik dalam pembuatannya, baik dari segi desain karakter, environment, dan user interface. Tipografi yang digunakan kurang cocok, tetapi tidak mengganggu jalannya permainan. Selain itu, kekurangan dari game "DreadOut" adalah gameplay yang kurang jelas dan sulit dimengerti oleh player. Beberapa player yang melakukan tes permainan yang bernamaLet's Play di akun Youtube terlihat berputar-putar di area yang sama karena petunjuk/objektif yang diberikan gim kurang dapat dimengerti. Alur cerita dalam "DreadOut" terlihat memiliki banyak klise layaknya dalam sebuah film horor pada umumnya, namun plot twist pada akhir cerita masih dapat menambah daya tarik bagi para pemain. Jadi, kekurangan dari game "DreadOut" adalah dari segi tipografi, gameplay dan storyline. 
Demikian tinjauan dari penulis, dengan adanya hasil analisa ini diharapkan dapat menjadi referensi bagi para pengembang permainan digital sehingga dapat menciptakan gim bergaya lokal selanjutnya dengan pertimbangan teori desain dan riset yang baik dari pembahasan yang dilakukan penulis.

\section{DAFTAR PUSTAKA}

\section{Buku}

Ambrose, Gavin dan Paul Harris. 2005. Basic Design 02: Layout. Singapura: AVA Publishing. 2005. Basic Design 03: Typography. Singapura: AVA Publishing.

O. Galitz, Wilbert. 2007. The Essential Guide to User Interface Design. Kanada: Wiley Publishing.

Rollings, Andrew dan Ernest Adams. 2003. On Game Design. Amerika Serikat: New Riders Publishing.

Rustan, Suryanto. 2009. Layout, Dasar \& Penerapannya. Jakarta: PT Gramedia Pustaka Utama. 2009. Mendesain Logo. Jakarta: PT Gramedia Pustaka Utama.

Safanayong, Yongky. 2006. Desain Komunikasi Visual Terpadu. Jakarta: Arte Intermedia.

Sihombing, Danton. 2015. Tipografi dalam Desain Grafis-Edisi Diperbaharui. Jakarta: PT Gramedia Pustaka Utama.

\section{Sumber Elektronik/Internet}

Andarwati, F. 2012. Video Games Dan Filsafat Pendidikan: Pendekatan Teori Simulacra Jean Baudrillad. http://www.academia.edu/6647047/. Diakses pada tanggal 17 Mei 2016.

Chandra, Reza. 2012. Konsep User Interface.http://reza_chan.staff.gunadarma.ac.id/. Diakses pada 14 Maret 2016.

Warman, Peter. 2015. Rolling IntoThe South Asian Games Market: Sizing Opportunities in the World's Fastest Growing Region.https://newzoo.com/wpcontent/uploads/2011/06/Newzoo_PG_Connects_Southeast_Asia_V1.pdf. Diakses pada 24April 2016.

Yusuf, Oik. 2014. Sebulan, Game Horor Indonesia Dulang $R p \quad 1$ Miliar.http://tekno.kompas.com/read/2014/07/17/09040067/sebulan.game.horor.indones ia. dulang.rp.1.miliar. Diakses pada 14 Maret 2016. 